\title{
TANTANGAN PENDIDIKAN KEWARGANEGARAAN PADA REVOLUSI 4.0
}

\author{
LAURENSIUS ARLIMAN S \\ Mahasiswa Pascasarjana Universitas Negeri Padang \\ laurensiusarliman@gmail.com
}

\begin{abstract}
Today there are more and more challenges of civic education in education, from elementary to tertiary education. This happens because education is increasingly developing in accordance with the development of pressology. Of course, this matter no longer recognizes national boundaries based on time and space. Technology today can help people meet from any country. For this reason, this article wants to see how the development of civic education in the revolutionary era 4.0 and the future challenges related to civic education in the revolutionary era 4.0. The research method used in this article is a quantitative educational method, supported by comparative materials from books and journal articles. The results show, First, the development of citizenship education in the revolutionary era 4.0 follows the times and technology, so that more flexible rules are needed and in accordance with the needs of citizens of the Republic of Indonesia. Second, the future challenge related to civic education in the revolutionary era 4.0 is to introduce what are the rights and obligations of citizens, so that citizenship education is mandatory to be taught at any level of education in Indonesia.
\end{abstract}

Keywords: Challenges, Citizenship Education, Revolution 4.0.

\begin{abstract}
Abstrak: Pada hari ini semakin banyak tantangan pendidikan kewarganegaraan di dalam bangku pendidikan, baik dari tingkat dasar sampai dengan pendidikan tinggi. Hal ini terjadi karena pendidikan yang semakin berkembang sesuai dengan perkembangan tekanologi. Tetunya hal ini tidak lagi mengenal batas-batas negara berdasarkan waktu dan ruang. Teknologi pada hari ini dapat membantu orang bertemu secara darig dari negara manapun Atas hal tersebut artikel ini ingin melihat bagaimana perkembangan pendidikan kewarganegaraan pada era revolusi 4.0 dan bagaimana tantangan kedepan terkait pendidikan kewarganegaraan pada era revolusi 4.0. Metode penelitian yang dipakai dalam artikel ini adalah metode pendidikan kuantitatif, dengan didukung dengan bahan-bahan perbandingand daai buku dan artikel jurnal. Hasil penelitian menunjukan, Pertama, perkembangan pendidikan kewarganegaraan pada era revolusi 4.0 mengikuti perkembangan zaman dan teknologi, maka dibutuhkan aturan yang lebih fleksibel dan sesuai dengan kebutuhan warganegara Republik Indonesia. Kedua, tantangan kedepan terkait pendidikan kewarganegaraan pada era revolusi 4.0 adalah mengenalkan apa saja yang menjadi hak dan kewajiban warga negara, sehingga pendidikan kewargangearaan wajib untuk diajarkan didalam level pendidikan apapun di Indonesia.
\end{abstract}

Kata Kunci: Tantangan, Pendidikan Kewarganegaraan, Revolusi 4.0.

\section{A. Pendahuluan}

Saat ini, negara sedang berkoar-koar tentang pembentukan karakter dan penerapan rasa nasionalisme yang lebih nyata di setiap lini kehidupan masyarakat, khususnya di bidang pendidikan. Lebih utama lagi dalam bidang Pendidikan

Kewarganegaraan (Simamora, 2014). Tantangan mengajar Pendidikan

E-ISSN: 2657-0300 Lembaga Penelitian dan Penerbitan Hasil Penelitian Ensiklopedia 333

P-ISSN: 2657-0319 
Kewarganegaraan di era milenial saat ini butuh usaha keras. Justru tantangan tersebut bukan datang dari materi atau kurikulum pendidikan kewarganegaraan itu sendiri. Melainkan dari kualitas sumber daya manusia yang kompeten, yaitu guru.

Selanjutnya, Pendidikan Kewarganegaraan di lingkup sekolah juga mengembangkan misi sebagai pendidikan bela negara, pendidikan multikultural, pendidikan lingkungan hidup, pendidikan hukum, dan pendidikan anti korupsi. Nah, dari berbagai misi tersebut timbul pertanyaan bagaimanakah pengajar masa kini, terutama guru Pendidikan Kewarganegaraan, bersinergi dan beradaptasi seiring perkembangan globalisasi dan perkembangan teknologi?

Pasal 37 ayat (2) Undang-Undang Nomor 20 Tahun 2003 Tentang Sistem Pendidikan Nasional ditegaskan, bahwa kurikulum pendidikan tinggi wajib memuat diantaranya pendidikan kewarganegaraan. Hal ini berarti pendidikan kewarganegaraan memiliki peran yang sangat penting dan strategis dalam pembentukan rasa nasionalisme dan pembentukan karakter (character building) bagi mahasiswa sebagai generasi penerus bangsa. Indonesia sebagai negara kesatuan yang memiliki kultur dan kepribadian yang terikat oleh Bhineka Tunggal Ika harus dapat mempersiapkan diri untuk mencegah setiap ancaman dan gangguan yang dapat memecah persatuan dan kesatuan bangsa diantaranya melalui pendidikan kewarganegaraan khususnya di perguruan tinggi.

Pendidikan Kewarganegaraan merupakan salah satu bidang kajian dalam konteks pendidikan nasional yang memiliki peran strategis bagi pembentukan karakter bangsa di tengah heterogenitas masyarakat Indonesia. Realitas pluralitas dan heteroginitas tersebut tergambar dalam prinsip Bhineka Tunggal Ika (Desmon, 2018). Untuk terlaksananya pendidikan kewarganegaraan yang baik tentunya diperlukan dosen yang memiliki kompetensi serta dalam proses pembelajaran antara lain kesiapan dalam mengajar, komunikasi, dan kepribadiaan dosen yang bersangkutan terutama dalam perkembangan teknologi di zaman revolusi industri 4.0.

Atas hal tersebut artikel ini bertujuan untuk melihat bagaimana perkembangan pendidikan kewarganegaraan pada era revolusi 4.0 dan bagaimana tantangan kedepan terkait pendidikan kewarganegaraan pada era revolusi 4.0 di Indonesia pada hari ini.

\section{B. Metodologi Penelitian}

Metode penelitian ini menggunakan metode deskriptif analitis dengan pendekatan kualitatif. Obyek penelitian dilakukan beberapa artikel dan buku ilmiah yang mendukung artikel ini, dengan subyek penelitian yang merupakan responden terdiri atas informan kunci, informan, dan peneliti sendiri. Teknik pengumpulan data terdiri dari data primer yang diperoleh dari responden dan data sekunder berupa literatur, jurnal ilmiah baik nasional maupun internasional. Penelitian ini tergolong dalam cross-section research, karena mengambil satu bagian dari gejala pada satu waktu tertentu. Penelitian ini dilakukan dalam waktu tertentu dan hanya dilakukan dalam satu kali waktu saja dan tidak akan melakukan penelitian lain di waktu yang berbeda untuk dijadikan perbandingan. 


\section{Hasil dan Pembahasan}

\section{Arah Konsep Perkembangan Pendidikan Kewarganegaraan Pada Era Revolusi}

\section{0}

Ada tiga komponen utama Pendidikan Kewarganegaraan, yaitu pengetahuan kewarganegaraan (civic knowledge), keterampilan kewarganegaraan (civic skills), dan sikap kewarganegaraan (civic disposition). Di era milenial ini, ketiga komponen tersebut akan lebih mudah dicerna dan diresapi anak didik dengan contoh nyata dan realis (Laurensius Arliman S, 2018). Tidak sekedar ceramah yang membosankan dan bikin kantuk. Logikanya, anak didik milenial yang memiliki lebih banyak pengetahuan dan sikap kewarganegaraan (Martaria Rizky Rinaldi, 2020) akan menjadi warga negara yang percaya diri (civic competence). Kemudian warga negara yang memiliki pengetahuan dan keterampilan kewarganegaraan akan menjadi warga negara milenial yang mampu (civic competence). Selanjutnya, warga negara milenial yang memiliki sikap dan keterampilan akan menjadi warga negara milenial yang komitmen (civic commitment).

Warga negara milenial yang memiliki pengetahuan, sikap dan keterampilan kewarganegaraan akan menjadi warga negara milenial yang cerdas dan baik ( smart and good citizenship). Itulah tujuan akhir mengajar Pendidikan Kewarganegaraan di era milenial, bila didukung juga oleh "smart and good teacher". Selain itu untuk mendukung itu semua maka dibutuhkan aturan yang lebih fleksibel dan sesuai dengan kebutuhan warganegara Republik Indonesia. Hal ini tentunya untuk mendukung perkembangan dan dinamika yang berkembang dalam pendidikan kewarganegaraan

Konsep pendidikan kewarganegaraan selama ini terdiri dari: Pertama, Bagi kaum kosmopolitanisme, akan menganggap setiap orang sebagai warga negaranya sendiri dan merasa berhak untuk menjamin nasib mereka semua tanpa kecuali (Hardi Alunaza SD, 2017). Kosmopolitanisme berasal dari kata kosmopolites yang berarti warga negara semesta. Di dalam kata ini terkandung pemahaman, bahwa manusia bukanlah semata anggota dari negara atau bangsa tertentu, tetapi ia, yang pertama dan terutama, adalah warga semesta. Kehadirannya tidak lebih tinggi dan tidak terpisah dari berbagai mahluk hidup lainnya. Sebaliknya, keberadaannya amat tergantung dari keberadaan mahluk hidup lainnya (Wattimena, 2018). Ketika diketahui bahwa orangorang yang tinggal di negara X mengalami penderitaan karena perlakuan semenamena oleh pemimpinnya, maka negara Y yang menganut doktrin kosmopolitanisme akan melakukan segala cara untuk menjatuhkan pemimpin negara $X$ dan menyelamatkan warga negara $X$ dari tirani. Ketika warga negara $Z$ kehilangan rumahnya akibat bencana alam, maka negara $\mathrm{Y}$ akan membuka lebar pintu imigrasinya, memberikan tempat tinggal baru bagi mereka di negara Y, dan memberikan mereka pekerjaan. Negara yang menganut doktrin kosmopolitanisme adalah ibarat Bapa di Surga Yang Maha Adil, mengasihi semua orang, dan membuka pintu rumahnya pada siapapun. Tidak ada kata 'orang asing' di dalam kamus kosmopolitanisme. Sementara itu, negara yang berpihak pada kubu komunitarianisme hanya akan peduli pada warga negaranya sendiri. Orang-orang yang berada di luar batas teritori mereka adalah orang asing layaknya alien yang tidak dapat dipahami, mereka berpotensi sebagai ancaman, dan harus diregulasi oleh undang-undang agar tidak menimbulkan permasalahan. Justifikasi yang diberikan untuk melegitimasi kebijakan yang terlihat 'kejam' ini adalah bahwa negara memiliki kontrak sosial dengan penduduknya dan oleh karenanya memiliki tanggung jawab untuk mendahulukan kepentingan mereka dibandingkan siapapun. Dalam kasus pelanggaran HAM yang dilakukan negara $\mathrm{X}$, negara $\mathrm{W}$ yang menganut doktrin komunitarianisme E-ISSN: 2657-0300 Lembaga Penelitian dan Penerbitan Hasil Penelitian Ensiklopedia $\quad 335$ 
tidak akan berbuat apa-apa. Mereka akan berargumen bahwa tidak ada gunanya menghabiskan sumber daya nasional untuk memenuhi kepentingan mereka yang bukan warga negaranya. Kemudian dalam kasus bencana alam di negara Z, negara W tidak akan membuka pintu imigrasinya dan berargumen bahwa membiarkan orang asing dalam jumlah besar memasuki teritorinya akan menciptakan potensi ancaman keamanan dalam negeri yang tidak diinginkan oleh penduduknya. Negara yang menganut doktrin komunitarianisme adalah ibarat seorang Don mafia yang menyayangi keluarganya melebihi siapapun namun tidak ragu untuk bersikap bengis kepada selainnya.

Kedua, Bagi kaum konservatif, ketidaksederajatan masyarakat merupakan suatu hukum keharusan alami, suatu hal yang mustahil bisa dihindari dan sudah menjadi ketentuan sejarah atau suratan takdir Tuhan. Perubahan sosial bukan hal yang harus diperjuangkan, karena hal itu akan membuat manusia lebih sengsara (Darmawan, 2017). Dalam bentuknya yang klasik, paradigma konservatif dibangun berdasarkan pandangan bahwa masyarakat pada dasarnya tidak dapat merencanakan perubahan atau memengaruhi perubahan sosial, karena hanya Tuhan yang dapat merencanakan keadaan masyarakat dan hanya Dia yang tahu makna di balik semua itu. Nasib manusia pada umumnya sudah ditentukan oleh Tuhan (Salim, dkk. 2007). Berdasarkan pandangan ini, kaum konservatif lama menganggap rakyat tidak memiliki kekuatan atau kekuasaan untuk mengubah kondisi mereka. Dengan kata lain, rakyat harus menerima nasibnya dengan pasrah dan mau menerima takdir Tuhan. Kaum konservatif berpendapat bahwa pendidikan bersifat a-politis. Lembaga pendidikan dibentuk untuk memahami ajaran Tuhan. Pendidikan bertujuan untuk menjaga status quo. Bagi kaum konservatif, orang miskin, buta huruf, tidak berpendidikan, dan kaum tertindas lainnya tidak memiliki kekuasaan atau power dikarenakan salah mereka sendiri. Namun demikian, kaum konservatif menyarankan kepada kaum miskin agar mereka bersabar dan belajar untuk menunggu sampai giliran mereka datang, karena pada akhirnya kelak semua orang akan dapat memperoleh kebebasan dan kebahagiaan. Jadi untuk mencapai kebebasan dan kebahagiaan, manusia harus belajar dan bekerja keras.

Ketiga, Paradigma Pendidikan Liberal, Kelompok ini berpendapat bahwa terdapat masalah di masyarakat, tetapi bagi mereka pendidikan tidak ada kaitannya sama sekali dengan persoalan politik dan ekonomi masyarakat. Tugas pendidikan tidak ada sangkut pautnya dengan persoalan politik dan ekonomi masyarakat. Namun demikian, kaum liberal selalu berusaha untuk menyesuaikan pendidikan dengan jalan memecahkan berbagai masalah yang ada dalam pendidikan dengan suatu usaha reformasi kosmetik (Fakih, dkk. 1999). Dalam reformasi kosmetik ini, strategi yang ditempuh di antaranya membangun kelas dan fasilitas baru, modernisasi peralatan sekolah, dan menyehatkan rasio guru-murid. Selain itu, juga dilakukan pelatihan yang lebih efisien dan efektif untuk mengembangkan pembelajaran yang berbasis kepada siswa. Kaum liberal beranggapan bahwa pendidikan bersifat a-politis dan tidak terkait dengan struktur kelas, dominasi politik dan budaya serta diskriminasi gender di masyarakat luas. Pendidikan di mata salah satu aliran liberal, yaitu structural functionalism, justru dimaksudkan sebagai media untuk mensosialisasikan dan mereproduksi nilai-nilai tata susila, keyakinan dan nilai-nilai dasar agar masyarakat luas berfungsi secara baik. Pendekatan liberal ini mendominasi segenap pemikiran mengenai pendidikan baik formal maupun non-formal (Mochamad Nasichin Al Muiz, 
2020). Akar pendidikan ini adalah filsafat politik liberalisme, oleh karenanya pengaruh liberalisme dalam pendidikan, terutama filsafatnya menjadi kuat. Hasil akhir dari pendidikan liberal adalah manusia rasionalis liberal, yang memenuhi ciriciri (1) bahwa semua manusia memiliki potensi sama dalam intelektual, (2) baik tatanan alam maupun norma sosial dapat ditangkap oleh akal, (3) manusia bersifat individualis, artinya manusia adalah atomistik dan otonom (Fakih, dkk. 1999). Lembaga pendidikan, terutama sekolah dibentuk sebagai ajang kompetisi individual. Kompetisi, prestasi, dan perankingan merupakan tiga hal yang dikejar dalam pendidikan liberal. Pendidikan liberal juga dipengaruhi oleh aliran positivisme, yaitu suatu aliran filsafat yang berakar pada tradisi ilmu-ilmu sosial yang dikembangkan dengan mengambil cara ilmu alam menguasai benda, dengan kepercayaan adanya universalisme dan generalisasi melalui metode determinasi dan fixed law atau kumpulan hukum teori (Fakih, dkk. 1999). Dalam hal ini, pengetahuan selalu mengikuti hukum ilmiah yang bersifat universal, prosedur kuantitatif, dan dapat diverifikasi dengan metode ilmiah (scientific). Pendek kata, paradigma pendidikan liberal bersifat positivistik. Pendidikan dilakukan seumur hidup dengan konsep andragogi, yang membuat manusia dewasa memperbaiki kemampuannya melalui pelatihan, manajemen, kewirausahaan, dan lain-lain (Salim, dkk. 2007).

Keempat, Paradigma Pendidikan Kritis, Dalam pandangan pendidikan kritis, manusia harus berjuang dalam hidupnya untuk mengatasi belenggu masyarakatnya. Paradigma kritis menghendaki perubahan struktur secara fundamental dalam politik ekonomi di mana pendidikan itu berada (Salim, dkk. 2007). Kekuatan dari paradigma ini adalah ketajamannya dalam membedah fenomena ketidakadilan dan ketimpangan sosial. Perubahan sosial harus direncanakan dengan baik dan bersifat memihak kepada rakyat kecil yang tertindas agar tercipta sistem baru yang lebih adil. Pendidikan sebagai bagian dari perubahan sosial harus dapat menciptakan kembali manusia yang bebas lepas dari belenggu pendidikan yang didominasi oleh negara dan pemilik modal. Pendidikan bagi penganut pendidikan kritis, merupakan arena perjuangan politik. Dalam paradigma kritis dikehendaki perubahan struktur secara fundamental dalam politik ekonomi masyarakat di mana pendidikan berada. Jika kaum konservatif dan liberal percaya bahwa pendidikan tidak terkait dengan persoalan ekonomi, politik, dan ketidakadilan gender, maka kelompok pendidikan kritis meyakini bahwa kelas dan diskriminasi gender tercermin dalam dunia pendidikan (Fakih, dkk. 1999). Dalam perspektif kritis, urusan pendidikan kewarganegaraan adalah melakukan refleksi kritis terhadap "the dominant ideology" ke arah transformasi sosial.

\section{Tantangan Kedepan Terkait Pendidikan Kewarganegaraan Pada Era Revolusi} 4.0.

Di Revolusi Industri 4.0 ini, kita memang dituntut untuk lebih kreatif, mandiri serta lebih pintar. Internet terutama sosial media merupakan salah satu contoh perkembangan teknologi di era ini, merupakan suatu hal yang tidak dapat dihindari dan seringkali dapat menjerumuskan masyarakat dalam jurang kesesatan dan ketidakmajuan.

Pada masa ini masyarakat dapat dengan mudah mengakses berita, semua orang telah memiliki gadget yang dapat digunakan, dari anak anak hingga orang dewasa dapat dengan mudah mengakses situs-situs tertentu dan dengan mudah menyebarkan informasi. Perkembangan teknologi di Revolusi Industri 4.0 ini tidak hanya memberikan sesuatu positif namun juga memberikan sesuatu yang negatif, belakangan 
ini banyak sekali berita - berita hoax yang tersebar, dan yang menyedihkan adalah kadang kita juga bingung untuk membedakan berita yang hoax dan berita yang benar (Kostina, E., Kretova, L., Teleshova, R., Tsepkova, A., \& Vezirov, 2015).

Pendidikan kewarganegaraan saat ini, karena dinilai kurang bermanfaat untuk melawan arus persaingan di masa Revolusi Industri 4.0. Dalam dunia Pendidikan, kebanyakan orang lebih melihat Nilai Pelajaran daripada nilai moral seseorang, lebih ingin tahu apakah nilainya bagus atau tidak ketimbang memperdulikan apakah nilai tersebut didapatkan dengan jujur atau tidak (Pangalila, 2017). Pola pikir masyarakat yang seperti inilah yang harus dirubah, masyarakat yang berpendidikan dan bermoral akan membangun Indonesia menjadi negara yang lebih baik lagi, dan sehingga masyarakat akan berfikir lagi dan takut untuk menyebarkan berita-berita hoax serta dapat menyaring manakah berita yang salah dan berita yang benar. Nah, disinilah peran tenaga pendidik dan orang tua sangat diperlukan.

Tenaga pendidik dan orang tua diharapkan dapat fleksibel dalam menghadapi perkembangan zaman, dan tetap mengutamakan Pendidikan moral dan karakter. Selain dari internet, televisi juga dapat menjadi masalah dalam Pendidikan moral dan karakter suatu generasi penerus bangsa, banyaknya tontonan yang tidak memberikan manfaat dan tidak sesuai dengan umur dapat memberikan masalah serius dalam moral serta karakter seorang anak.

Orang tua harus memantau kegiatan anaknya dalam menggunakan media hiburan dan informasi, apakah telah sesuai dengan usianya dan bermanfaat kah konten tersebut untuk dilihat (Kostina, E., Kretova, L., Teleshova, R., Tsepkova, A., \& Vezirov, 2015). Orang tua dan tenaga pendidik diminta untuk dapat memanfaat perkembangan teknologi untuk kelangsungan masa depat anak, tenaga pendidik dapat mengajarkan peserta didik untuk belajar membuat blog atau belajar design untuk mengasah kreatifitas peserta didik dan dapat mengisi waktu luang agar dapat digunakan dengan baik.

Diperlukan kerjasama antara masyarakat dan pemerintah agar revolusi industri 4.0 ini dapat memberikan banyak manfaat bagi negara terutama pada generasi penerus bangsa. Salah satu caranya adalah dengan penanaman Pendidikan Moral dan kewarganegaraan sejak dini, generasi yang bermoral dan berkarakter akan mampu bersaing dalam lingkup global serta dapat membangun Indonesia menjadi negara yang lebih baik lagi.

\section{Penutup}

Hasil penelitian menunjukan, Pertama, perkembangan pendidikan kewarganegaraan pada era revolusi 4.0 mengikuti perkembangan zaman dan teknologi, maka dibutuhkan aturan yang lebih fleksibel dan sesuai dengan kebutuhan warganegara Republik Indonesia. Kedua, tantangan kedepan terkait pendidikan kewarganegaraan pada era revolusi 4.0 adalah mengenalkan apa saja yang menjadi hak dan kewajiban warga negara, sehingga pendidikan kewargangearaan wajib untuk diajarkan didalam level pendidikan apapun di Indonesia.

\section{Ucapan Terimakasih}

Terimakasih kepada Bapak Dr. Isnarmi M.Pd dan Bapak Dr. Junaidi Indrwati S.Pd, M.Pd pada mata kuliah Analisis Teori dan Pengembangan Keilmuan PPKN di 
Program Pascasarjana Prodi PPKN di Universitas Negeri Padang, yang memberikan kami kesempatan untuk bisa menulis artikel.

\section{Daftar Pustaka}

Darmawan, A. B. dan C. (2017). Revitalisasi Paradigma Konservatif Pendidikan Demokrasi Pada Pkn Dengan Inovasi Media Pembelajaran. Jurnal Ilmiah Pendidikan Pancasila Dan Kewarganegaraan, 2(2).

Desmon, A. (2018). Penafsiran Konstitusi Dalam Bingkai Hukum Pancasila. Jurnal Cendekia Hukum, 3(2).

Hardi Alunaza SD, M. S. (2017). Globalisasi Sebagai Katalis Kosmopolitanisme Dan Multikulturalisme: Studi Kasus Resistance Cina Terhadap Kosmopolitanisme. , Intermestic: Journal of International Studie, 1(2).

Kostina, E., Kretova, L., Teleshova, R., Tsepkova, A., \& Vezirov, T. (2015). Universal Human Values: Cross-Cultural Comparative Analysis. Jurnal Procedia - Social and Behavioral Sciences, 214(1), 1019-1028.

Laurensius Arliman S. (2018). Perlindungan Hukum Bagi Anak dalam Perspektif Pancasila dan Bela Negara. Jurnal Ilmu Hukum Unifikasi, 5(1), 58-70.

Martaria Rizky Rinaldi, R. Y. (2020). Kecemasan pada Masyarakat Saat Masa Pandemi Covid-19 di Indonesia. APPTI, 1(1).

Mochamad Nasichin Al Muiz, M. M. (2020). Pendekatan Konservatif dalam Pendidikan Islam (Kajian Teori Al Muhafidz Al-Ghazâli dalam Pendidikan Islam). Jurnal Penelitian, 14(1), 1-25.

Pangalila, T. (2017). Interaksi Sosial Dosen dan Mahasiswa Dalam Proses Perkuliahan Di Jurusan PPKn FIS UNIMA. Jurnal PKn Progresif, 12(2).

Simamora, E. (2014). Hak Pemerataan Pendidikan Di Indonesia (Tinjauan Terhadap Pasal 31 Undang-Undang Dasar Negara Republik Indonesia 1945). Jurnal Advokasi, Sekolah Tinggi Ilmu Hukum Padang, 5(2), 2014.

Wattimena, R. A. . (2018). Kosmopolitanisme Sebagai Jalan Keluar Atas Tegangan Abadi Antara Neokolonialisme, Radikalisme Agama, Dan Multikulturalisme. Jurnal Ledalero, 17(7), 7-8. 